\title{
Prerequisites for the Development of the Innovation Activity of Enterprises in the Conditions of the Digital Economy
}

\author{
Arefieva O.V., Piletska S.T., Miahkykh I.M., Arefiev S.O
}

\begin{abstract}
The article deals with the essence of the digital economy on the basis of research of theoretical approaches, their systematization from the point of view of introduction of information resources and platforms, and from the viewpoint of introduction of qualitative changes in production relations. The conclusions state that the innovative activity of enterprises in the period of digital transformation of the economy is a system of measures aimed at supporting the innovative activity of enterprises in order to achieve long-term goals of their operation, connected with the implementation of innovative methods of work, which contribute to ensuring the production and competitiveness. The digital economy contributes to the commercialization of current knowledge of enterprises, technologies and equipment. The prerequisite for their efficient functioning is the development of innovative activity of enterprises, which contributes to the development of innovative products with new qualities and reduces the diffusion of innovation. In the context of the digital economy, support for the innovation activity of enterprises plays an increasingly important role in ensuring the functioning of complex production and economic systems, which is the enterprise. The implementation of the suggested approach to the development of innovative activity of the enterprise requires significant accounting for specific accumulated knowledge and is more mobile to change information in the decision-making process.
\end{abstract}

Keywords: competitiveness, digital competencies, economic security, innovation

\section{INTRODUCTION}

The institutional structure of a transformational society has its own peculiarities and requires the formation of a digital economy, which, in turn, necessitates the digitalization of enterprises, which contributes to increasing their competitiveness in the domestic and foreign markets and provides for a high concentration of knowledge-intensive production, knowledge, competences and technologies. At the same time, the level of innovative development of the existing enterprises does not fully meet the expectations related to the formation of a new economy of innovative type. In this situation, the digitalization of businesses is becoming a necessary instrument that can stimulate their acceptance to innovation and increase their innovation activity as a whole. Therefore, the necessity to identify the prerequisites for the

Revised Version Manuscript Received on October 15, 2019.

Arefieva O.V. National Aviation University, Kyiv, Ukraine. (Email: lena-2009-19@ukr.net)

Piletska S.T., National Aviation University, Kyiv, Ukraine. (Email 0508486185@ukr.net)

Miahkykh I.M., Kyiv National University of Technologies and Design, Kyiv, Ukraine. (Email: mred_1965@@i.ua)

Arefiev S.O., Kyiv National University of Technologies and Design, Kyiv, Ukraine. (Email: arefievso@ukr.net) development of innovative activity of enterprises in the digital economy and making the necessary management decisions on this basis are of particular significance.

\section{LITERATURE REVIEW}

The digital economy is a driving force of innovation, competitiveness and economic growth for business structures. Despite the high practical importance and significance of the study of the digital economy, there is no uniquely defined definition in the academic community. For example, authors such as Apalkova V.V., Gudz A.E., Kolyadenko S.V. in the works $[1,5,10]$ consider the manifestation of the digital economy through substantiation of tasks and measures for changing values, priorities and guidelines of creating qualitatively new models of enterprise management on the basis of modern digital technologies. However, it should be noted that such a definition does not reveal the possibilities and prerequisites for adapting enterprises to them as well as the possibility of realizing the obtained competitive advantages.

According to the authors Voynareko M.P., Skorobogaty L.V. Putsentylo, P.R., Humeniuk O.O. [4, 14] the digital economy supposes that all economic processes (except for the production of goods) occur independently of the real world. Products and services have no physical media and are "electronic" ones. It is substantiated that the digital economy is based on the widespread use of automatic systems, devices and equipment using computing and control units and devices capable of functioning without human involvement. It should be noted that the processes of automation, digitalization do not include and do not emphasize the need to acquire digital competencies on the basis of which innovations can be implemented.

Despite the fact that it has been given some attention to the substantiation of the essence, constituent priorities and orientations of the digital economy, insufficient scientific approaches are devoted to substantiating the place and role of innovative activity of enterprises in the period of introduction of digital economy technologies. 


\section{FORMULATION OF RESEARCH OBJECTIVES}

The aim of the article is to summarize the approaches to the essence of the digital economy, to substantiate the prerequisites for its development, to offer approaches for the implementation of its components and model elements and interconnections of innovation activity of enterprises in the digital economy.

To achieve this goal have been determined following tasks: in order to achieve this goal the following tasks have been determined: to reveal the essence of digital economy based on the study of theoretical approach; systematize the influence and characteristics of the digital economy; provide an economic model of the elements and interconnections of development of the enterprises innovative activity in the conditions of digital economy.

\section{PRESENTATION OF THE MAIN RESEARCH MATERIAL}

Transformation of the country's economy on the basis of digital economy is necessary to ensure qualitative and quantitative changes of the market participants, formation of new competitive advantages, a basis for the implementation of innovative management, which, in turn, causes the adaptation of business models and strategic sets of enterprises. The application of digital technologies to the management of economic systems requires the harmonization of the system of ensuring both sustainable functioning, overcoming the dangers of environmental impact, and the introduction of new architectonics of the organization of labor of all workers of enterprises.

The essence of the digital economy is considered by the authors-economists from the standpoint of introducing information resources and platforms, and from the viewpoint of introducing qualitative changes in industrial relations. Through the viewpoint of practical use, leading Ukrainian scientists consider digital economy to enhance the performance of economic entities, namely, S. Veretyuk [3] and L. Keith [9] believe that digital economy is a transformation of all spheres of the economy through the transfer of information resources and knowledge on a computer platform for the future use. Scientists Puntenteilo P.R., Humeniuk O.O. [14] determine that the digital economy is the communication medium of economic activity on the Internet, the result of the transformational effects of new general-purpose technologies in the fields of information, communication and nanotechnology. The essence and definition of a digital platform have been revealed.

According to S.V. Kolyadenko [10], the studies conducted using the digital economy have the ability to quickly adapt to the real economy and enable the real sectors of the economy to find ways to overcome the crisis in the recession wave of the world economic development.

The works of such scientists as Kraus N.M., Goloborodko A.P., Kraus K.M. [12], Dzhusov O.A. [7], S.P. [1] are devoted to the problem of theory of those practices of investment and innovative activity of enterprises and the possibilities of its actualization. They pay attention to adaptations to environmental factors, which also include elements of the digital economy, which implies the development and implementation of appropriate economic mechanisms. Thus, Kraus N.M., Goloborodko O.P., Kraus K.M. emphasized that the digital economy is taking the avant-garde tendencies, has identified key areas of the early stage of the digital economy, and substantiated and disclosed products and services that produce the given economy as a set of innovative trends. Dzhusov O.A., Apalkov S.S. have theoretically substantiated the main changes in the international economic relations of the subjects of international investment activity at the present stage of formation of the global digital economy.

The development of the digital economy in today's economic environment, characterized by large-scale creation of information, the development of technologies capable of generalizing it have created the prerequisites for the spreading of these technologies to all spheres of life, which are the driving force of social development and changes in the formations of the economy, which allows the rapid completion of the post-industrial stage. Global trends confirm the necessity and possibility of introducing comfortable business conditions and restructuring of network-type business models. Removal of information barriers and possible job creation in different countries require re-thinking both the content and appearance of the enterprise itself, as well as the configuration and having jobs of remote access.

One of the European Commission's top priorities is to remove regulatory and other barriers to creating a Digital Single Market over the coming years. The implementation of this initiative could bring in $€ 415$ billion annually to the EU economy, as well as contribute to the creation of hundreds of thousands of new jobs. But these benefits should not be confined to EU borders. It will bring economic growth, job creation, better living conditions and easier business. For Ukraine, it will mean a more sustainable political environment and significant progress towards social and economic modernization [15].

As a prerequisite for introducing the benefits of the digital economy into all sectors of the economy, it is advisable to modify mechanisms capable of integrating and actively involving the integral components of the knowledge economy in the form of human capital through the use of high-tech industries, dynamic means of information generation and processing as a source of new knowledge and competencies that are based on economic culture (Fig. 1). The transition to consumer personalization and maximum satisfaction of its needs is possible through ideological support for the transition to the digital economy, which will also contribute to the development of human potential through digital competencies. 


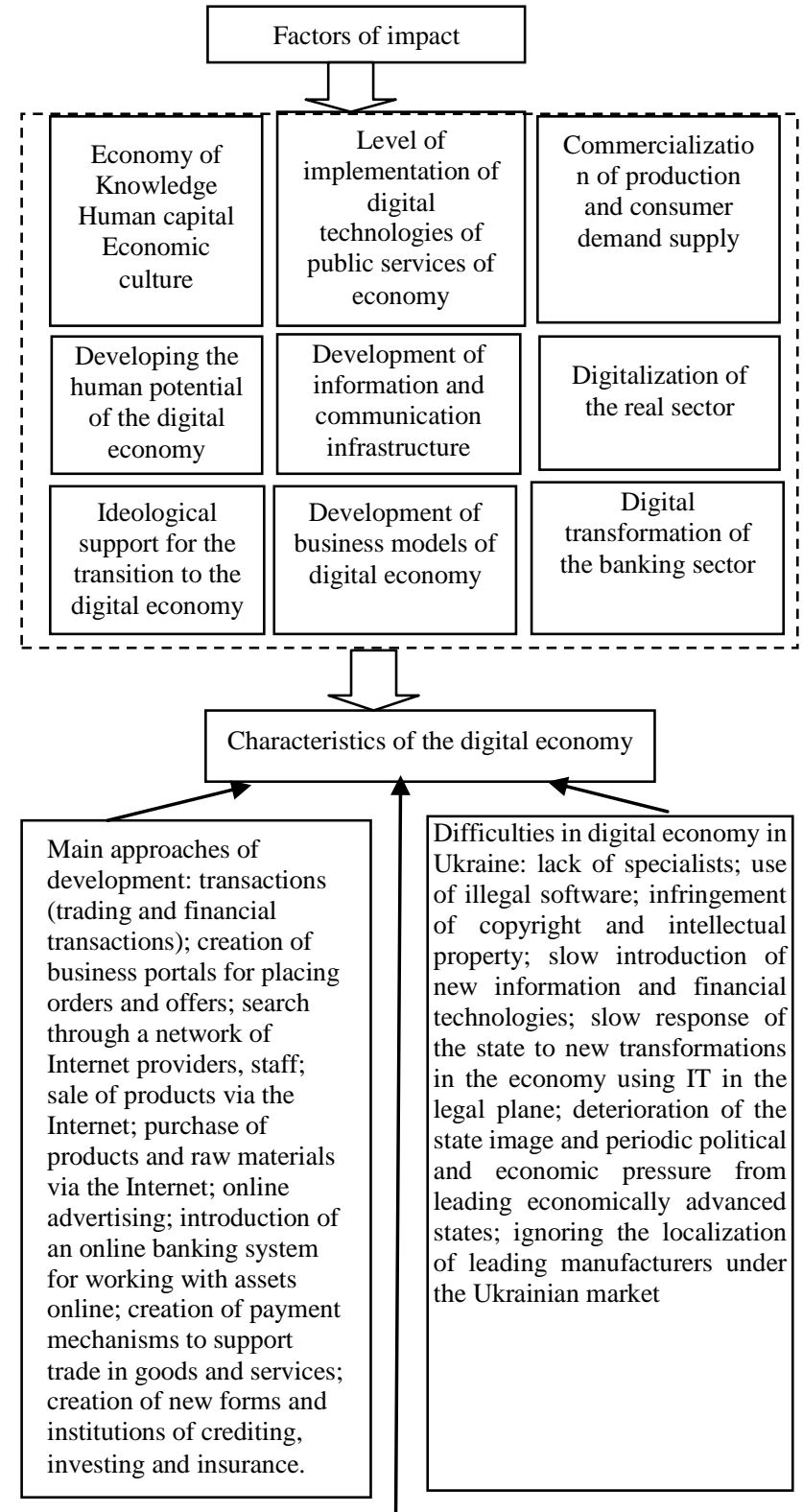

System of support: legal, organizational, technical, technological, financial, personnel, cyber-security

\section{Fig. 1. Digital economy impact and characteristics system}

Improved on the basis of $[5$, P. 6, 14]

Along with components that reflect the impact and participation of people (enterprise staff), it is necessary to take into account characteristics that are based both on the development of information and communication infrastructure and on the level of implementation of digital technologies of public services of the economy. Thus, the International Organization for Economic Cooperation and Development (OECD) identifies three key components of digital economy [16]: supportive infrastructure (hardware and software, telecommunications, networks, etc.); e-business (conducting business activities and any other business processes through computer networks); e-commerce (distribution of goods via the Internet). The development of business models of the digital economy causes changes in the logic of competence formation and their use in the business processes of the enterprise, which provides for increasing its innovative activity. This is possible on the basis of understanding the business model as a changing way of forming the value chain through digitalization when choosing suppliers, buyers and product promotion systems, and pricing based on an adapted innovative concept of consumer value management. Therefore, based on the above-mentioned items, we can conclude that the digital economy in the context of enterprise innovation development should be understood as a set of activities based on digital technologies, as well as infrastructure that ensures the functioning of digital technologies and directly influences the prerequisites for innovative enterprise development. Digital technology, in this case, should be understood to mean technologies that are related to the creation, collection, processing, storage and transmission of information based on digital systems that carry comprehensive data on the state of innovation of the economy and its impact on the innovative development of enterprises.

It should be noted that the way of digitalization for each enterprise will be individual in both approach and time, but transformation is necessary, and the main thing for the managers of enterprises is the awareness of the expediency and relevance of measures to actively introduce new technologies into production. The creation of an external climate oriented to the digitalization of enterprises through the formation of regulatory framework, as well as the natural processes of digitalization of the society will provide in the near future the dropout of enterprises producing low quality products, not interested in improving the competitiveness of production [8, p. 15].

Digitalization of the real sector is possible through the commercialization of production and consumer demand-supply, as well as a necessary condition as a source of financial resources and creation of capital of enterprises digital transformation of the banking sector. With the introduction of digital services, commercial banks are in the avant-garde, which is improving the system of ensuring continuous access of the client to credit resources and payment system. At the same time, V.A. Kornovskaya believes that the bank ceases to be an intermediary at the digital stage of development. Communication with a bank is limited to the submission of appropriate commands performed in the digital technology system. The client becomes in some way autonomous, independent in relation to the bank [11, p. 255]. At the same time, the traditional service is changing qualitatively for the service with more mobile characteristics such as price reduction, availability, possibility of timely control of current accounts and credit resources. However, the bank has certain advantages in controlling the client's cash flow and paying capacity and maintaining financial discipline.

Applying a networking approach is advisable to increase business efficiency in all market segments. This is an important feature of the digital age: on the one hand, never before has the network been so critical to business success, and on the other hand, it has never been so demanding. The network must continually learn in real time using automation 
and artificial intelligence. By interpreting the administrator's intentions and real behavior of resources, users, traffic, such a network will continuously improve security and accelerate the execution of operational processes. The cycle of information on the network allows you to accumulate analytical materials on the basis of which decisions are made and predictions are made [2].

The expansion of digital technologies and their introduction into the everyday life of a person transforms his inner and outer world, which will buy more individual things. This is facilitated by: individualization of production - the products produced will meet the needs of each individual consumer; virtually augmented reality creates a selective individual world for each person, as well as his or her behavior, becomes more "digitalized", analyzed, controlled, approached and regulated, and consequently, the person loses his or her identity; the gradual alienation of the inner world from man; empowerment of the authorities to segregate people, identify and shape their life paths, as well as the necessary workers; enhancing the polarization of human communities [6, P.67]. It should be added that not all industries are differentiated, as there is widespread demand for certain groups of products related to food, pharmaceutical, construction and others. Certain issues in this context relate to the operational and financial support of the production cycles of machines with a long technological cycle.

The digitalization of economy and society leads to the fact that the creation or improvement of technologies and methods cannot be a source of competitive advantage for enterprises for a long time, their constant development is necessary. The benefits of technological progress will be much broader and longer lasting if it is possible to create an innovative environment that enhances the innovation activity of enterprises.

Nowadays, the intensification of business activities implies an increase in the degree of openness and interaction with partners. The complexity and versatility of such interaction convinces the feasibility and effectiveness of the network approach. In fact, the network approach is a response to the challenges of today, changing business conditions and expectations in uncertain and intense threats and information in the economic space. In fact, it involves the use of one type of horizontal integration, which maximizes the attraction of available resources, the development of innovations and competencies, competitive advantages, innovation, production, information and intellectual potential in the context of a single multipolar information and communication space. Among the notable advantages of the network approach are the increased organizational capacity, more efficient use of resources, increasing competitiveness, expanding the horizon of opportunities to solve complex business problems and improving the quality of products and services for consumers [5, pp. 8-9]. All this should be on an innovative basis and on the basis of innovative activity of enterprises.

Realizing the benefits of the digital economy helps accelerate the entry to a new level of technological development and innovation, and their introduction by the enterprise. Search of the best production solutions from an environmental point of view leads to technological renewal of production processes, as well as to the emergence of innovative products [13, P.71].

The development of the digital economy, in addition to the need for digital competencies, forms the need to accelerate the movement of technologies based on the digital economy, to improve the business models of enterprises. The digital economy involves the widespread accumulation and processing of digital data, providing a fundamentally new (high) quality of goods and services in all areas. Innovative activity is possible with appropriate creation of conditions for information security and stimulating effects of the state, strengthening of protection of intellectual property, improvement of business models of enterprises and improvement of quality of life through saving of time. It is advisable to consider the benefits of the digital economy from the economic and social angles, which allows to combine economic transformations at the enterprise level and social adaptation of the personnel to the organization of changes in economic activity (Fig. 2).

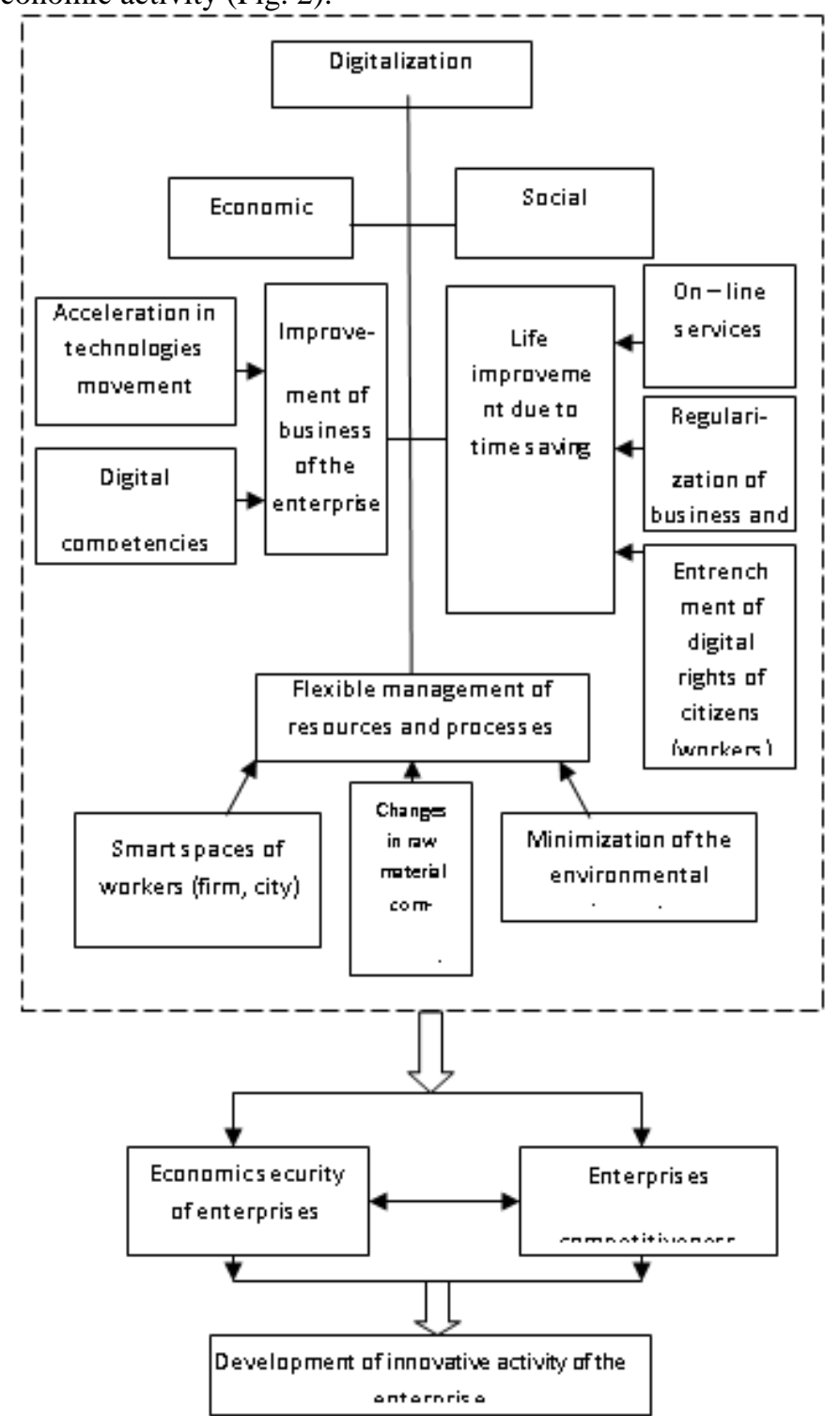

Fig. 2. Economic model of the elements and interconnections of development of innovative activity of enterprises

Published By:

Blue Eyes Intelligence Engineering 
Flexible management of resources and processes that provide enterprise innovation is one of the most important benefits that the digital economy can have for an enterprise, namely, maximizing employee competencies, reducing inventory levels, changes in raw material composition, reasonable worker space, and more. It is important that the desired effect can only be achieved by digitalizing the value chain throughout the chain. An intelligent resource management system must rely on quality data on the actual state of the equipment, loads and competencies of people, their real capabilities on the basis of reasonable indicators. Automatic updating of which will facilitate timely decision-making on maintaining the continuity and rhythm of activity, as well as expanding the sphere of innovative activity of the enterprise.

The transition to a digital economy is connected with increased competition between businesses. In order to win the competition, the company needs to create an effective economic security system that responds promptly to emerging threats in the digital economy. Management of competitiveness in the digital economy is one of the main aspects of the enterprise activity, which is determined primarily by the efficiency of production potential, the success of financial activities, the competitiveness of manufactured products and its quality, efficiency of marketing activities. The ability to manage competitiveness is based on the use of modern management instruments, which causes a reduction of environmental impact in order to develop innovative activity of enterprises.

The main factors that help to increase the innovation activity of enterprises in the digital economy are: the removal of barriers to business activity through the possibility of online communication, which accelerates the elimination of contradictions and reduces the time for negotiation and agreement, which facilitates the diffusion of innovations and their commercialization; global access to resources without intermediaries, which saves resources and promotes greater pricing and logistical awareness; possibility of prompt search of investors, including foreign ones; reducing the cost of innovative products and reducing the timing of their production and distribution; accelerating the promotion of innovative products through the introduction of global advertising also on social networks if it is relevant to consumer demand; entering new markets and expanding business partners based on a concerted intention to do business.

Thus, the development of innovation activity of enterprises in the digital economy cannot be carried out without increasing their competitiveness, the introduction of digital technologies, innovation in management and production, which contributes to improving economic security in competition.

Implementation of measures to improve the competitiveness of the enterprise in the digital economy is associated with the emergence, processing and transmission of large amounts of information, which allows to identify the enterprise as an information system that requires the development of sophisticated software that can accumulate and update status information, methods, participants in the process of managing as well as assess the power and results of the impact, analyze and evaluate the impact of the external and internal environment on development and innovative activity of enterprises.

\section{CONCLUSION}

Innovation activity of enterprises in the period of digital economic transformation is a system of measures aimed at supporting the innovative activity of enterprises in order to achieve long-term goals of their operation related to the introduction of innovative working methods that contribute to the production of innovative products and increase competitiveness. The digital economy contributes to the commercialization of current knowledge of enterprises, technologies and equipment. The prerequisite for their efficient functioning is the development of innovative activity of enterprises, which contributes to the development of innovative products with new qualities and reduces the diffusion of innovation.

In the context of the digital economy, support for the innovation activity of enterprises plays an increasingly important role in ensuring the functioning of complex production and economic systems, such as the enterprise. Information and its efficient use become a strategic resource for those enterprises that are transitioning to intellectual management, as the market structures change, the qualitative components of the segments in which the enterprise operates, the role of unique advantage is enhanced. The implementation of the suggested approach to the development of innovative activity of the enterprise requires significant accounting for specific accumulated knowledge and is more mobile to change information in the decision-making process.

\section{REFERENCES}

1. Apalkova, V.V. (2015): Conception of the development of digital economy at European Union and perspectives of Ukraine. Periodical of Dnipropetrovsk University: Management of innovations, 4, pp. 9-18.

2. Bodnar, O. (2018): Digitalization and business competitiveness are key drivers of the development of Ukrainian economy. Available at <https://business.ua/person/\%20item/2452-tsifrovizatsiya -ta-konkurentospromozhnist-biznesu-klyuchovi-drajverirozvitku-ukrajinskoji-ekonomiki>

3. Veretiuk, S., Pilinsky, V. (2017): Identifying priority directions of the digital economy in Ukraine. Financial area. Scientific notes of the Ukrainian Communication Research Institute, 3 (27), pp. 51-58.

4. Voinarenko, M.P. (2015): Net tools for capitalization of informational and intellectual potential and innovations. Periodical of Khmelnitsky National University: Economic sciences, vol. 3, no. 3, pp. 18-24.

5. Gudz, O.E. (2018): Digital Economy: Changing the Values and Guidelines of Enterprise Management. Economy, Management, Business, 2 (24), pp. 4-12.

6. Humeniuk, O. (2018): Problems and perspectives of the development of digital economy. Digital economy: trends and perspectives, pp. 66-68.

7. Dzhusov, O.A., Apalkov, S.S. (2016): The digital economy: structural shifts in the international capital market. International relations: Economic sciences, 9. Available at:
Blue Eyes Intelligence Engineering \& Sciences Publication 
$<$ http://journals.iir.kiev.ua/index.php/ec_n/article/view/3 $\underline{058 / 2746>}$

8. Ignatova, G.V. (2015): Causes of appearance of quality reserves in industrial enterprises. Factors of success, 2 (5), pp. 15-18.

9. Kit, L.Z. (2014): Evolution of net economy. Periodical of Khmelnitsky National University: Economic sciences, vol. 2, no. 3, pp. 187-194.

10. Koliadenko, S.V. (2016): Digital economy: prerequisites and stages of establishment in Ukraine and in the world. Economic, Finance, Management, 6, pp. 105-112.

11. Kornivska, V.O. (2017): Digital banking: risks of financial digitalization. Problems of economy, 3, pp. 254-261.

12. Kraus, N.M., Goloborodko, O.P., Kraus, K.M. (2018): Digital economy: trends and perspectives of the abangard change of development. Digital economy, 1. Available at: 〈http://www.economy.nayka.com.ua/pdf/1_2018/8.pdf >

13. Lepeiko, T.I., Mazorenko, O.V. (2017): Development of enterprise as a social and ecological system in the conditions of instability. Mechanism of Economic Regulation, 3, pp. 65-73.

14. Putsentylo, P.R., Humeniuk, O.O. (2018): Digital economy as a new vector of reconstruction of traditional economy. Innovative economy, 5-6 (75), pp. 131-143.

15. Digital Cooperation: Ukraine and EU prepare common project in the sphere of digital market. Available at: <http://www.eurointegration.com.ua/articles/2016/06/29/ 7051397/>

16. The Concept of a "Digital Economy". Available at: http://odec.org.uk/theconcept-of-a-digital-economy 